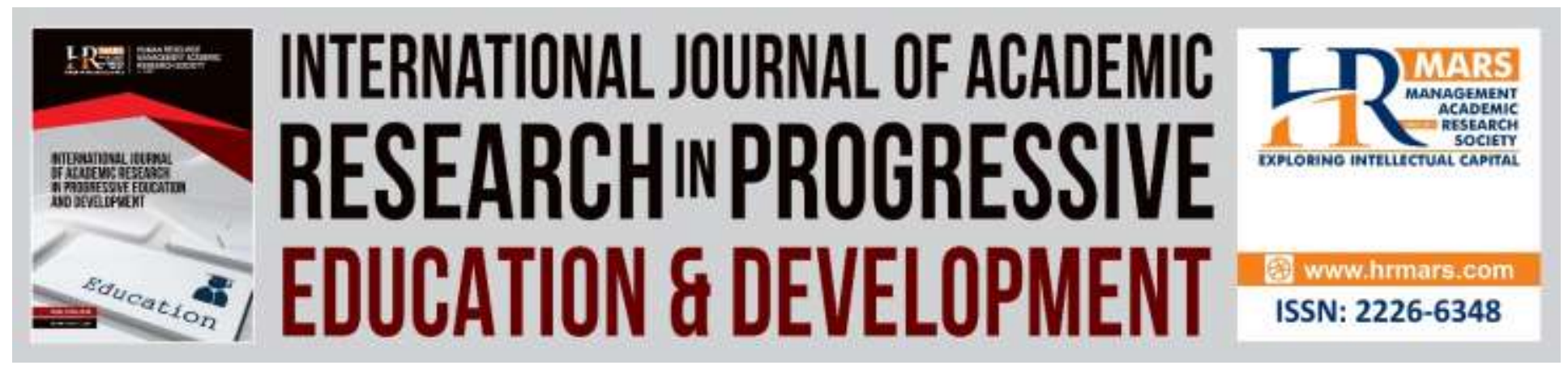

\title{
Translation, Validity and Reliability of Evaluation Process within Supervisory Inventory (EPSI) among Trainee Counselors in Public Universities in Malaysia
}

Suhaili Arifin, Sidek Mohd Noah, Wan Marzuki Wan Jaafar, Noor Syamilah Zakaria

To Link this Article: http://dx.doi.org/10.6007/IJARPED/v8-i3/6429

DOI: $10.6007 /$ IJARPED/v8-i3/6429

Received: 03 August 2019, Revised: 19 August 2019, Accepted: 01 September 2019

Published Online: 06 September, 2019

In-Text Citation: (Arifin, Noah, Jaafar, \& Zakaria, 2019)

To Cite this Article: Arifin, S., Noah, S. M., Jaafar, W. M. W., \& Zakaria, N. S. (2019). Translation, Validity and Reliability of Evaluation Process within Supervisory Inventory (EPSI) among Trainee Counselors in Public Universities in Malaysia. International Journal of Academic Research in Progressive Education and Development, 8(3), 352-363.

Copyright: (C) 2019 The Author(s)

Published by Human Resource Management Academic Research Society (www.hrmars.com)

This article is published under the Creative Commons Attribution (CC BY 4.0) license. Anyone may reproduce, distribute, translate and create derivative works of this article (for both commercial and non-commercial purposes), subject to full attribution to the original publication and authors. The full terms of this license may be seen at: http://creativecommons.org/licences/by/4.0/legalcode

Vol. 8(3) 2019, Pg. $352-363$

http://hrmars.com/index.php/pages/detail/IJARPED

JOURNAL HOMEPAGE

Full Terms \& Conditions of access and use can be found at http://hrmars.com/index.php/pages/detail/publication-ethics 


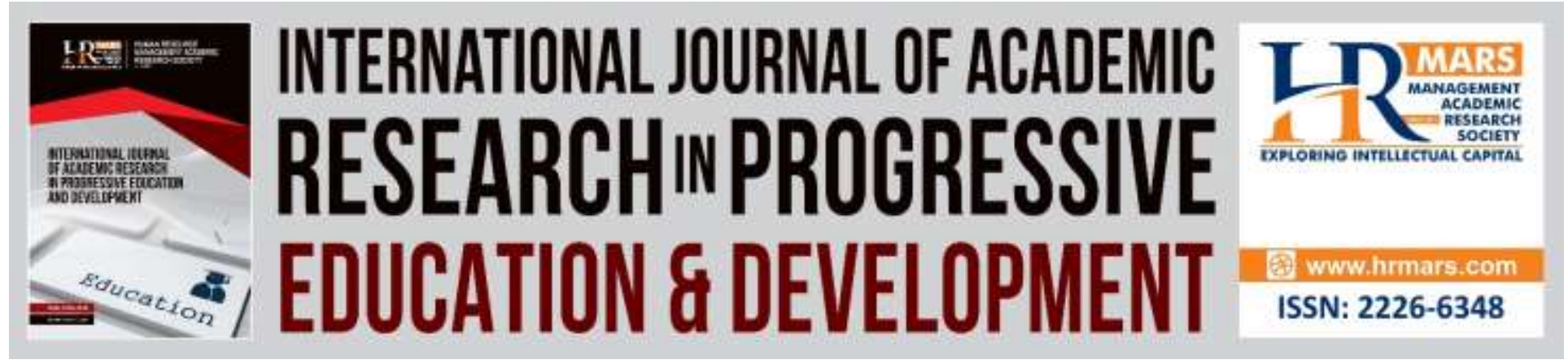

\title{
Translation, Validity and Reliability of Evaluation Process within Supervisory Inventory (EPSI) among Trainee Counselors in Public Universities in Malaysia
}

\section{Suhaili Arifin, Sidek Mohd Noah, Wan Marzuki Wan Jaafar, Noor Syamilah Zakaria}

Department of Counselor Education and Counseling Psychology, Faculty of Educational Studies, University of Putra Malaysia,Malaysia

\begin{abstract}
This study is carried out to translate the Evaluation Process Within Supervisory Inventory (EPSI) from English version to Malay language, then to test validity and reliability of the instrument. This EPSI is developed by Lehrman-Waterman \& Ladany (2001) to measure the perception and experience of the trainee counselor towards the evaluation process in the clinical supervision. The translation procedure in this study uses the back-to-back translation method with the appointment of six experts from the counseling field. All these experts are proficient and fluent in both languages based on the local values and culture. The first phase involves three experts translating the EPSI into Malay language, whereas the rest of the experts retranslated the instrument back to English. For content validity, the EPSI already translated in Malay language is sent to the three other experts in the field for the evaluation of the item content and the subscale used in the instrument. The result indicates the coefficient value of content validity obtained for each item is high with maximum value $=.933$ and minimum value $=.767$, while the coefficient value for each sub scale also high with goal setting $=.890$ and feedback $=.883$. Finally, the reliability value of EPSI in the pilot study for goal setting $\alpha=.958$ and feedback $\alpha=955$; whereas in the actual study, for goal setting $\alpha=.846$ and feedback $\alpha=.840$ respectively. These values indicate that EPSI is a consistent instrument. In conclusion, other than successfully translating the Evaluation Process within Supervisory Inventory into the local context, this study also proves that the instrument also has good validity and reliability. Hence, it can benefit and applicable for Malaysian trainee counselors.

Keywords: Translation, Validity, Reliability, Evaluation Process within Supervisory Inventory, Trainee Counselors
\end{abstract}




\section{Introduction}

Evaluation is one of the basic elements in clinical supervision and it is also defining components for clinical supervision (Bernard \& Goodyear, 2009; Welfare, 2010). According to Muraskin (1993), he defined evaluation as "the systematic collection and analysis of data needed to make decisions, a process in which most well-run programs engage from the outset" (p. 4). In the field of counselor education and supervision, the process of evaluation is defined as a systematic procedural implementation to access the professional development of a student (Choate, Smith, \& Spruill, 2005). Irrefutably, the process of evaluation has been cited the main cause for anxiety among trainee counselors (Caroll, 1996); which is can trigger a negative experience in the supervision (Magnuson, Wilcoxon, \& Norem, 2000); incite risks to law and ethical violation (Adam, Foster, \& Ward, 2007); and cause grievances to the trainee counselors (Ladany, 2004). However, Bradley \& Ladany (2001) stated that the evaluation process can be seen as an effort that enables the supervisor to monitor the performance of trainee counselors with their clients, provide clinical skills training, rectify any errors or mistakes on the part of the trainee counselors, and determine the fate of the trainee counselors in the training program. Furthermore, an evaluation is also found to be a potential stimulation for the change in trainee counselors (Holloway 1992), increase the satisfaction in supervision, and improve the supervision relationship between the supervisor and the trainee (Lehrman-Waterman \& Ladany, 2001).

Meanwhile, Falender (2014) emphasized on the actual role of the supervisor in the evaluation process. He asserted that other than the responsibility to monitor and assess trainees in the evaluation process, a supervisor also has to make sure that a trainee counselor is informed if he or she fails to reach the standard and they need to be transferred to the rehabilitation status on the competency area that has been identified. The writer also added that all information related to the assessment cannot reasonably be seen as a shock because as a trainee he or she has to receive continuous evaluation, feedback, and monitoring. Madani (2008) stated that there should be consent between supervisor and trainee counselor on the content to be learned and anything to be evaluated in the supervision. Next, based on the Code of Ethics (American Counseling Association (ACA), 2014), there is a special allocation with regard to the assessment in clinical supervision as contained under section F.6.a. Evaluation which is: "Supervisors document and provide supervisees with ongoing feedback regarding their performance and schedule periodic formal evaluative sessions throughout the supervisory relationship" (p.12).

In Malaysia, there is also an allocation regarding the assessment dictated in the Counselor Code of Ethics (Board of Counselor (Malaysia), 2011) under section F.9.a. Evaluation which is: "Counselor educator must state clearly to the students, before and after the training program, the level of competency required, the method of assessment and the table of evaluation for didactic and clinical competency. They also have to give some feedback about the evaluation and the assessment of performance throughout the training program" (p.33). Based on both of the Code of Ethics, clearly evaluation is something very significant and stands prominently as the main core in the clinical supervision process. Indirectly, it is shown that the responsibility shouldered by the counselors and supervisors is arduous since it does not only help stimulate the growth of trainee counselors, but also seeks to address clients' wellbeing and charity as well as 
the gatekeeper to this profession as dictated in ACA (2014) and Board of Malaysia (2011). Therefore, the process of evaluation is regarded as a nucleus in the clinical supervision (Bernard \& Goodyear, 2009). The writer also holds the opinion that it is one "primary vehicle" for the supervisors to deliver any information about the many stages of development of a trainee counselor. Realizing the importance of evaluation on the effectiveness of the clinical supervision process to the development of trainee counselors, Lehrman-Waterman \& Ladany (2001) have developed an instrument the Evaluation Process within Supervisory Inventory (EPSI). The purpose of EPSI is to access the extent of experience of trainee counselors towards the evaluation process that has been received in the clinical supervision by the supervisor. With this measurement tool, it is anticipated that the evaluation practice in clinical supervision can be operationalized and implemented effectively and efficiently (Lehrman-Waterman \& Ladany, 2001). EPSI contains 21 items (14 positive items and 7 negative items) and measures two subscales which are goal setting; and feedback.

For the goal setting sub-scale, it is very much linked with the evaluation planning. This is because in carrying out supervision, the supervisor or trainee counselors need to refer to the evaluation planning which contains several pieces of information that have been determined. Goal setting in supervision refers to a contract comprising of the criteria set to be evaluated, the supervision method that will be adopted when making evaluation, the duration of time and the frequency of meeting set for supervision and the method of summative evaluation that can be implemented in the supervision. Other than that, an effective goal setting applies when the goals intended are not rigid and changeable based on supervision requirements and involving a mutual agreement, also it needs to be clear earlier on in the supervisory relationship (Bernard \& Goodyear, 1998). It is better for goal setting to be measurable, more specific such as containing the tasks and responsibilities that can be fulfilled, and according to the priorities. All these characteristics contained in goal setting will be those that facilitate the trainee counselors to face any ambiguity or expectation in the supervision. Meanwhile, feedback is the mainstay in evaluation because it is the point of view of the supervisor on the progress achieved and also the weakness that has to be overcome in supervision (Bernard \& Goodyear, 2014); it is also an ongoing process of evaluation related to growth and professional development of trainee counselors in the training program (Swank \& McCarthy, 2013). Effective feedback has to be consistent, objective, and based on the standard (Lehrman-Waterman \& Ladany, 2001); it is not biased, clear and can be understood, balanced between positive and negative feedback, and needs to be comprised of formative and summative assessments (Bernard \& Goodyear, 1998); and constructive (Bernard \& Goodyear, 2004; Phelps, 2013).

\section{Problem Statement}

The standard accreditation, for instance Council for Accreditation of Counseling and Related Educational Programs (CACREP) (2016), and Counselor Training Standard and Qualification (Board of Counselor (Malaysia), 2015), as well as the Code of Ethics by ACA (2014), and Board of Counselor (Malaysia) (2011) have made evaluation, a mandatory requirement in clinical supervision. Based on this guideline, it will be daunting to the counselor educator and supervisor, even the trainee counselors to obey and adhere to it. This is because the evaluation 
process in the supervision itself is highly complex and involves a multi-dimensional factor. In the previous literature, the evaluation is prominent as an aspect that can facilitate growth, especially in enhancing the competency of trainee counselors such as knowledge, skills, attitude and values. Until today, counselors' development and competency level still stand as the main issues as found in Falender (2014); Bernard \& Goodyear (2009); Gonsalvez \& Crowe (2014); Benshoff \& Paisley (1996). When these issues emerge, the question is just how far will the process of evaluation in clinical supervision be effective? The effectiveness implied here is concerned with achievability and practicality of trainee counselors on the aim and objectives targeted, and covering the feedback on anything a trainee counselor needs in the evaluation process.

The best approach is to consider the evaluation process that happens from the perspective of the trainee counselors themselves. According to Falender (2014), the selfexposure of trainee counselors becomes a critical aspect in the supervision due to the fact that in most of the clinical supervision the majority of the supervisors have not directly observed the trainees and only did their review trough the video, but also based on the genuine exposure of the trainees themselves. This indicates that the evaluation process done in the clinical supervision also depends on the trainee counselors' own experiences and perceptions. Therefore, it is reasonable for trainee counselors' opinions to be considered in the supervision evaluation process, as focused by Lehrman-Waterman \& Ladany (2001) who have developed the Evaluation Process Within Supervisory Inventory (EPSI) for the purpose. Despite that, there are some issues emerging as the EPSI developed by Lehrman-Waterman \& Ladany (2001) is foreignbased, where the language, values and culture would be the main obstacles if it is to be applied to Malaysian trainee counselors. Additionally, the literature review shows that there is the absence of studies that translate the EPSI with a more standard, systematic approach that weighs upon language uniformity, the values and culture in this country. These factors cause the instrument to be very restricted and even difficult to be applied to the local context. Based on the issues highlighted, it is thought that the EPSI need to be translated, validity and reliability tested so that it is relevant, easy and more accurate to be applied to the trainee counselors in this country. The study objectives are as follows:

a. To translate the measurement tool Evaluation Proses Within Supervisory Inventory (EPSI) from English language to Malay language

b. To analyze EPSI's content validity

c. To analyze EPSI's reliability value

\section{Research Method}

This study uses the descriptive design to obtain the content validity and analyze the reliability of the translated EPSI. Apart from that, the procedure in this study involves three main stages in achieving the objectives formed. The study area and respondents for Stage I comprised of six expert translators; two of them from UPSI, two from UNIMAS, one from USIM, and another one from UPM. Stage II involved three expert evaluators of content validity from UKM, UUM, and UIA. For the final stage of the study, there were two phases of data collection. The first phase was the pilot test involving 30 trainee counselors from UPSI, whereas the second phase was the actual study involving 367 trainee counselors selected through the simple random sampling 
technique. All the trainee counselors selected received their first degree from the counseling program accredited by Board of Counselors, Malaysia and Malaysia Qualification Accreditation (MQA) from nine public universities all over Malaysia. The universities are Universiti Putra Malaysia (UPM), Universiti Pendidikan Sultan Idris (UPSI), Universiti Sains Malaysia (USM), Universiti Malaya (UM), Universiti Utara Malaysia (UUM), Universiti Malaysia Sabah (UMS), Universiti Malaysia Sarawak (UNIMAS), Universiti Malaysia Terengganu (UMT), Universiti Sains Islam Malaysia (USIM), as well as Universiti Islam Antarabangsa Malaysia (UIAM). There are two measurement tools used in the study:

a. Evaluation Process Within Supervisory Inventory (EPSI) translated into Malay language

b. Validation Evaluation Form with a scale from 1 to 10; scale 1 (strongly disagree) to scale 10 (strongly agree)

This study employs three stages procedure namely- Stage I: translating the EPSI; Stage II: analyzing its content validity; and Stage III: analyzing its reliability value.

\section{Stage I}

Prior to the translation, six potential panel experts were identified. They were first contacted to ask for their consent on being the translators of the study measurement tool. An appointment letter was issued by the Supervisory Committee Chairman as the agreement was obtained. The six panel experts-cum-translators were lecturers who have $\mathrm{PhD}$ in education, specializing in the field of counseling psychology, and at the same time are proficient in both Bahasa Malaysia and English. The back-to-back translation process was carried out as emphasized by Brislin, Lonner and Thondike (1973) in two phases. The first phase began with three of them translating the original EPSI which is from English language to Malay language. The three translation texts were studied and purified in terms of the language consistency so that it will be appropriate with the value, the local culture, encompassing the counseling context and not deviating from the original instrument. The purification process has the aim of obtaining only one Malay language version that is the most identical with the original version. Next, the second phase took over. In this second phase, EPSI in Malay language version translated and revised was sent to the other three panel experts. The task this time was to retranslate it to English. This is to ensure that the EPSI in Malay language translation was retranslated to English so this last translation would resemble the original EPSI. Then, both the original and the English measurements were compared to strengthen to process of refining the EPSI in the version of Malay language. The aspects of refining and uniformity were analyzed again with reference to the local culture, based on the counseling field and identical with the meaning of the original measurement. After both phases of translation were approved, the EPSI then ready to undergo the process of content validity.

\section{Stage II}

In general, validity means that the instrument is measuring what it is supposed to measure (Borderns \& Abott, 2014). Babbie (2014) defines validity as an objective measurement and it can measure a concept empirically. In other words, an instrument is only valid if it can measure accurately the study variables. For studies that have high instrument validity, this will make the studies more meaningful (Cohen, Manion, \& Morrison, 2007; Ahmed, Khalid, Ammar, \& Shah, 2017). Researchers were recommended to refer to experts to assess validity through the 
consensus that every item contained in an instrument represents a concept or a construct that is to me measured (Creswell, 2008). Based on Polit, Beck \& Owen (2007) a universal agreement between three or four experts in the field is required. Thus, a total of three panel experts in the field of counseling who are really experienced as academicians were identified and they agreed to be appointed as the supervisor to determine the validity value of EPSI content. In carrying out the content validity analysis, every expert will be given the validation evaluation form with the scale of $1=$ strongly disagree to $10=$ strongly agree. In this validation evaluation form there are EPSI items (Malay language version) that was already translated, EPSI items (original version), also experts' written columns. The validity evaluation process began when these experts revised, criticized and agreed upon the content of EPSI. All forms of comments and suggestions of the experts were considered to improve the quality of EPSI being translated. To obtain the content validity of every item, the value of agreement for every item from all the three experts must be added, then divided by the total maximum value of agreement. Meanwhile, to obtain the content validity of every sub-scale, all validity values obtained for every item are added then divided by the total items of the sub-scale.

\section{Stage III}

Next, stage III is carried out to achieve the final objective of the study which is to obtain the reliability value of the translated EPSI. Reliability applies when the scores obtained from a measurement tool are consistent and stable (Creswell, 2012). A measurement tool has high reliability if the measurement is repeated under the same circumstances yet in different times, and still manages to produce the same score (Bordens \& Abott, 2014; Babbie, 2014; Creswell, 2012). Thus, to ensure that all the translated items of EPSI are really consistent and stable, the Malay-translated EPSI was tested in a pilot study before it was distributed in the actual study among the trainee counselors. A pilot study was done on 30 trainee counselors from UPSI who were undergoing internship and were supervised by the counseling lecturer there. This pilot study was carried out in UPSI considering that it was the only university that offered internship training at the time. Meanwhile, in the actual study, there are 367 trainee counselors from nine public universities in Malaysia chosen.

\section{Research Findings \\ Stage I}

After every step in the translation procedure has been followed and carried out in detail and by sequence, this study has successfully translated EPSI into Malay language from the original version in English. The EPSI that has successful been translated represents the local value and culture, and based on the counseling context that has been endorsed by the six experts that have fulfilled the criteria to be appointed as the translators of the instrument. The number of EPSI items translated full resembles the original EPSI developed by Lehrman-Waterman \& Ladany, (2001) comprising of 21 items (14 positive items, 7 negative items) measuring two sub-scales: (1) goal setting ( 13 items); and (2) feedback ( 8 items). Table 1 shows the breakdown of the sub-scale EPSI, the number of items for every sub-scale, and the negative items are the ones marked *. Before the score is counted, the negative items marked * must be recoded beforehand. The calculation of scores in EPSI is based on the seven-point Likert scale starting from 1 = strongly 
INTERNATIONAL JOURNAL OF ACADEMIC RESEARCH IN PROGRESSIVE EDUCATION AND DEVELOPMENT

Vol. 8, No. 3, 2019, E-ISSN: 2226-6348 @ 2019 HRMARS

disagree; and 7 = strongly agree. The higher the score obtained for every sub-scale, the higher the level of agreement of the trainee counselors on the sub-scale.

Table 1: Sub-scale and item of EPSI

\begin{tabular}{|c|c|}
\hline Sub-scale & Item \\
\hline Goal Setting & $1,2,3,4,5^{*}, 6^{*}, 7,8^{*}, 9,10^{*}, 11^{*}, 12^{*}$, dan 13 \\
\hline Feedback & $14,15,16,17^{*}, 18,19,20$, dan 21 \\
\hline
\end{tabular}

\section{Stage II}

For the content validity, three experts or evaluators have done an examination with several recommendations for improvement for the items contained in the Malay version of EPSI. This is to attend to the suggestions raised by Polit et al., (2007) who require three or four experts in the field to evaluate the item and measurement construct validity. Every member of the panel has given their agreement on the evaluation form validation distributed. The content validity value for every item and the content validity for all items for the sub-scale are found in Table 2 and 3 below:

Table 2: Content Validity Value of Every Item

\begin{tabular}{|c|c|c|c|}
\hline $\begin{array}{c}\text { Item in goal } \\
\text { setting subscale }\end{array}$ & $\begin{array}{c}\text { Content validity value } \\
\text { of every item }\end{array}$ & $\begin{array}{c}\text { Item in feedback } \\
\text { subscale }\end{array}$ & $\begin{array}{c}\text { Content validity value of } \\
\text { every item }\end{array}$ \\
\hline 1 & .800 & 14 & .767 \\
\hline 2 & .900 & 15 & .900 \\
\hline 3 & .900 & 16 & .867 \\
\hline 4 & .900 & 17 & .867 \\
\hline 5 & .800 & 18 & .867 \\
\hline 6 & .867 & 19 & .933 \\
\hline 7 & .933 & 20 & .933 \\
\hline 8 & .900 & 21 & .933 \\
\hline 9 & .900 & & \\
\hline 10 & .900 & & \\
\hline 11 & .900 & & \\
\hline 12 & .933 & & \\
\hline 13 & .933 & & \\
\hline
\end{tabular}

Table 3: Content Validity Value of Every Sub-scale

\begin{tabular}{|c|c|}
\hline Sub-scale & Content Validity Value of Every Sub-scale \\
\hline Goal setting & .890 \\
\hline Feedback & .883 \\
\hline
\end{tabular}

The study outcome demonstrates that the content validity value for every item is high which is .80 and above except for item 14 with the value of .767. Meanwhile, the value of the content validity for all items for every sub-scale also exceeds .80. Based on Polit et al., (2007), if the content validity value for every item is .80 and above from three or four experts, it shows that 
Vol. 8, No. 3, 2019, E-ISSN: $2226-6348$ @ 2019 HRMARS

the items have good validity, while the overall validity with the value .70 and above enables the content of the item to be accepted. Based on the finding obtained in this study, automatically it is proven that the EPSI translated into Malay language has high quality content validity value which fulfills the requirements to measure the evaluation process in clinical supervision.

\section{Stage II}

Stage III is where a test is carried out on the reliability of EPSI. According to Sidek (2011), the reliability of the measurement tool is high if a variable or an idea can be measured consistently or producing the same score. In turn, if the score varies, it means that the measurement tool has low, inconsistent reliability. The reliability value in this study is based on Alpha Cronbach or $\alpha$ coefficient at significant level .05. According to Cohen et al., (2007), coefficient $\alpha$ represents the correlation degree between the instrument items. The higher the value of $\alpha$, the higher the correlation between the items. This means that the items are reliable in measuring the same construct, and the same applies to the value. Cohen et al., (2007) proposed that the interpretation of coefficient $\alpha$ is established as follows:

Table 4: Alpha Cronbach Coefficient Interpretation

\begin{tabular}{|c|c|}
\hline Value $\alpha$ & Interpretation \\
\hline$>.90$ & Very highly reliable \\
\hline $.80-.90$ & Highly reliable \\
\hline $.70-.79$ & Reliable \\
\hline $.60-.69$ & Marginally/minimally reliable \\
\hline$<.60$ & Unacceptably low reliability \\
\hline
\end{tabular}

Table 5: EPSI Reliability Value

\begin{tabular}{|c|c|c|}
\hline Sub-scale & Pilot Study $(n=30)$ & Actual Study $(n=381)$ \\
\hline Goal Setting & .968 & .846 \\
\hline Feedback & .955 & .849 \\
\hline
\end{tabular}

In Table 5, the reliability value in the pilot study for the sub-scale goal setting $\alpha=.968$ and feedback $\alpha=.955$, whereas in the actual study the sub-scale goal setting $\alpha=.846$ and feedback $\alpha=.849$. The finding shows that the value $\alpha$ for both sub-scales of goal setting and feedback in the pilot study and actual study can be regarded as high. Here, it can be concluded that all the items contained in the EPSI possess good reliability value.

\section{Discussion}

The translation of the EPSI from English to Malay language has been a tremendous contribution to the counseling education field in Malaysia especially in the discipline of clinical supervision. Through this translation, it enables the evaluation process in the counseling supervision in this country to take place two-way, where the trainee counselors are no longer a subject for evaluation, but they are also responsible as evaluators towards the evaluation practice that has been carried out among supervisors. This is because the majority of them have the tendency to regard that evaluation is a one-way street one done only by the supervisors. 
Thus, this measurement outcome indirectly helps raise the awareness among lecturers, supervisors and counselor educators in this country to evaluate the weaknesses and strengths that can be improved in the upcoming supervision processes. Such awareness is crucial to make sure that the aim of the supervision which is to facilitate development and the competency of trainee counselors is effective and achievable. This fact is consistent with the outcome of the study by Lehrman-Waterman \& Ladany, (2001); Ahmed, Majid, \& Zin (2016) whereby the effectiveness of the evaluation in the supervision of trainee counselors is instrumental to the strong working alliance in the supervision, correlates significantly with the level of satisfaction of trainee counselors with the supervision, and correlates with the supervisor's influence on the trainee counselors' self-efficacy. All components make up the basis in producing good quality and efficient supervision.

Other than that, the study finding fills the gap as put forth in Ladany \& Malouf (2010), that until today studies done on supervision and more systematic or pragmatic methods are still very scarce. Therefore, the EPSI adds to the number of studies on supervision using a more systematic method because the procedure adopted in translating this study is a standard one, structured and proven empirically on the values and culture of the local trainee counselors through the validity and the reliability tests. The EPSI content validity analysis shows a high acquisition value for all the items and the whole item of each sub-scale. For the content validity of every item, the maximum value $=.933$, whereas the minimum value $=.767$. Meanwhile, for the content validity of every sub-scale the goal setting and feedback are also high with the values .890 and .883 respectively. With these values, there is proof that every item and sub-scale found in the EPSI represents the content that is to be measured. The study findings support the views held by Bernard \& Goodyear, (1998) and Lehrman-Waterman \& Ladany (2001) regarding the goal setting sub-scale; also the opinions of Lehrman-Waterman \& Ladany (2001); Phelps (2013); Bernard \& Goodyear (2014); and Swank \& McCarthy, (2013) with regard to the sub-scale of feedback where both are components that represent the process that happens in the supervision evaluation. Last but not least, the EPSI reliability analysis is also done twice, which is in the pilot test and in the actual study. The value outcome for the reliability analysis for every sub-scale of EPSI obtained by both studies is high and exceeds the minimum value as proposed by Cohen et al., (2007) $\alpha=.60$ to.69 automatically showing that it is a consistent and efficient instrument.

\section{Conclusion}

Conclusively, the study outcome has successfully translated the EPSI in the context of Malaysia in terms of the language, value and culture and focused on the field of counseling supervision. We can also conclude that the items and sub-scales contained in the EPSI are proven to be valid empirically, can be trusted and can be applied in practice to evaluate the experiences and perceptions of trainee counselors towards the evaluation process in this country's clinical supervision.

\section{Corresponding Author}

Name: $\quad$ Suhaili Arifin

Affiliation: Department of Counselor Education and Counseling Psychology, Faculty of Educational Studies, University of Putra Malaysia. 
INTERNATIONAL JOURNAL OF ACADEMIC RESEARCH IN PROGRESSIVE EDUCATION AND

DEVELOPMENT

Vol. 8, No. 3, 2019, E-ISSN: 2226-6348 @ 2019 HRMARS

Country: Malaysia.

E-mail ID: suhaili@ymail.com

Address: $\quad$ Lot 36, Jalan Surau Haji Yaakub, Kg. Tebauk, Bukit Tunggal, 21200 Kuala Nerus, Terengganu, Malaysia.

\section{References}

Ahmed, U., Khalid, N., Ammar, A., \& Shah, M. H. (2017). Assessing moderation of employee engagement on the relationship between work discretion, job clarity and business performance in the banking sector of Pakistan. Asian Economic and Financial Review, 7(12), 1197-121. https://doi.org/10.18488/journal.aefr.2017.712.1197.1210

Ahmed, U., Majid, A. H. A., \& Zin, M. M. (2016). Moderation of meaningful work on the relationship of supervisor support and coworker support with work engagement. The Journal of Business, Economics, and Environmental Studies (JBEES), 6(3), 15-20.

American Counseling Association. (2014). Code of Ethics. Alexandria, VA: Author.

Babbie, E. R. (2014). The basic of social research. (6 $6^{\text {th }}$ ed.). Belmont, CA: Wadsworth Cengage Learning.

Benshoff, J. M., \& Paisley, P. O. (1996). The structured peer consultation model for school counsellor. Journal of Counselling \& Development, 74(3), 314-318.

Bernard, J. M., \& Goodyear, R. K. (1998). Fundamentals of clinical supervision (2nd ed.). Carmelle, IN: Allyn \& Bacon.

Bernard, J. M., \& Goodyear, R. K. (2009). Fundamentals of clinical supervision (4th ed.). Upper Saddle River, NJ: Pearson.

Bernard, J. M., \& Goodyear, R. K. (2014). Fundamentals of clinical supervision (5th ed.). Boston: Pearson.

Bernard, J. M., \& Goodyear, R. K. (2004). Fundamentals of clinical supervision (3rd ed.). Boston Allyn \& Bacon.

Board of Counselor (Malaysia) (2011). Counselor Code of Ethics. Kuala Lumpur. Board of Counselor Publication.

Board of Counselor (Malaysia) (2015). Counselor Training Standard and Qualification. Putrajaya: Board of Counselor.

Bordens, K., \& Abott, B. B. (2014). Research design and methods: A Process approach. (9th ed.). New York, NY: McGraw -Hill.

Bradley, L. J., \& Ladany, N. (2001). Counselor supervision: Principles, process and practice ( $3^{\text {rd }}$ ed.). New York: Brunner-Routledge.

Brislin, R. W., Lonner, W. J. \& Thondike, R. M. (1973). Cross cultural research methods. New York: John Wiley \& Sons.

Caroll, M. (1996). Counseling Supervision: Theory, skills, and practice. London, UK: Casell.

Choate, L. H., Smith, S. L., \& Spruill, D. A. (2005). Professional development of counselor education students: An exploratory study of professional performance indicators for assessment. International Journal for the Advancement of Counselling, 27(3), 383-397.

Cohen, L., Mannion, L., \& Morrison, K. (2007). Research Methods in education. (6 $6^{\text {th }}$ ed.). Abingdon: Routledge. 
INTERNATIONAL JOURNAL OF ACADEMIC RESEARCH IN PROGRESSIVE EDUCATION AND DEVELOPMENT

Vol. 8, No. 3, 2019, E-ISSN: 2226-6348 @ 2019 HRMARS

Council for Accreditation of Counseling and Related Educational Programs. (2009). CACREP 2009 standards. Diakses pada Mac 20, 2016, daripada

Creswell, J. W. (2012). Educational research: Planning, conducting and evaluating quantitative and qualitative research ( $4^{\text {th }}$ ed.). Boston: Pearson Education.

Falender, C. A. (2014). Clinical supervision in a competency-based era. South African Journal of Psychology, 44(1) 6-17.DOI: 10.1177/0081246313516260.

Gonsalvez, C. J., \& Crowe, T. P. (2014). Evaluation of psychology practitioner competence in clinical supervision. American Journal of Psychotherapy, 68(2), 177-193.

Holloway, E. L. (1992). Supervision: A way of teaching and learning. In S. D. Brown \& R. W. Lent (Eds.), Handbook of counseling psychology (pp. 177-214). New York, NY: John Wiley \& Sons. http://www.cacrep.org/2009standards.html

Ladany, N. (2004). Psychotherapy supervision: What lies beneath. Psychotherapy Research, 14, 1-19.

Ladany, N., \& Malouf, M. A. (2010). Understanding and Conducting Supervision Research. In: Ladany, N., \& Bradley, L. J. (4 ${ }^{\text {th }}$ ed.), Counselor Supervision (pp. 353-388). New York, US: Routledge, Taylor \& Francis Group.

Lehrman-Waterman, D., \& Ladany, N. (2001). Development and validation of the evaluation process within supervision inventory. Journal of Counseling Psychology, 48, 168-177.

Magnuson, S., Wilcoxon, S. A., \& Norem, K. (2000). A profile of lousy supervision: Experienced counselors' perspectives. Counselor Education and Supervision, 39, 189-202.

McAdams, C. R., Foster, V. A., \& Ward, T. J. (2007). Remediation and dismissal policies in counselor education: Lesson learned from a challenge in federal court. Counselor Education and Supervision, 46(3), 212-229.

Muraskin, L. D. (1993). Understanding Evaluation: The Way to Better Prevention Programs. Retrieved April 29, 2019, from https://files.eric.ed.gov/fulltext/ED361604.pdf

Phelps, D. L. (2013). Supervisee experiences of corrective feedback in clinical supervision: A consensual qualitative research study. (Doctoral Dissertation The lowa State University) Digital Dissertation UMI 3493809.

Polit, D. F., Beck, C.T., \& Owen, S. V. (2007). Is the CVI an acceptable indicator of content validity? Appraisal and recommendations. Research in Nursing \& Health, 30 (4), 459-467.

Swank, J. M., \& McCarthy, S. N. (2013). The counselor feedback training model: Teaching counseling students feedback skills. Adult span Journal, 12, 100-112. DOI: 10. 1002/j.2161 0029.2013.00019.x.

Welfare, L. E. (2010). Evaluation in supervision. In: Ladany, N., \& Bradley, L. J. (4 ${ }^{\text {th }}$ ed.), Counselor Supervision (pp. 337-351). New York, US: Routledge, Taylor \& Francis Group. 